\section{Conflicto e intervención en el mercado de la leche en la Ciudad de México, 1902-1952}

\section{Conflict and intervention in the milk market in Mexico City, 1902-1952}

\author{
Maria del Pilar Zazueta ${ }^{i}$ \\ ' LLILAS-Benson/The University of Texas at Austin. \\ Austin - TX - EEUU \\ orcid.org/0000-0002-5577-6100 \\ pzazueta@utexas.edu
}

ZAZUETA, Maria del Pilar. Conflicto e intervención en el mercado de la leche en la Ciudad de México, 1902-1952. História, Ciências, Saúde - Manguinhos, Rio de Janeiro, v.28, n.4, out.-dez. 2021, p.1165-1182.

\section{Resumen}

En la primera mitad del siglo $\mathrm{XX}$, las autoridades de la Ciudad de México lucharon por regular el mercado de la leche con el fin de aumentar la oferta y la higiene del producto. Este proceso se caracterizó por amargas disputas entre el gobierno y todos los actores involucrados en la producción, venta, distribución y pasteurización de la leche de vaca. En este artículo explico cómo las prioridades económicas y políticas para el gobierno mexicano, es decir, proteger los precios al consumidor así como evitar el descontento entre los actores involucrados en el negocio, tuvieron primacia frente a las medidas de salud pública, como la pasteurización y la lucha contra la adulteración.

Palabras clave: leche; pasteurización; comercio; México; siglo XX.

\section{Abstract}

In the first half of the nineteenth century, authorities in Mexico City struggled to regulate the milk market in order to increase the product's availability and sanitation. This process was characterized by bitter disputes between the government and all actors involved in the production, sale, distribution and pasteurization of cow's milk. In this article I explain how the Mexican government's economic and political priorities, namely protecting consumer prices and avoiding discontent among the dairy business actors, were prioritized over public health measures, such as pasteurization and the struggle against adulterated milk.

Keywords: milk; pasteurization; business; Mexico; twentieth century. 
$\mathrm{D}$ urante la primera mitad del siglo XX los consumidores de la capital mexicana sospechaban seriamente de la calidad de la leche, incluso si estaba pasteurizada. En 1936, un columnista del periódico El Universal Gráfico resumió "el problema de la leche" argumentando que era inconcebible que el gobierno permitiera que "los habitantes fueran ... envenenados con la leche ... un artículo de primera necesidad." La leche, al ser tan nutritiva, además se debía "poder obtener al precio más reducido posible" (Cervantes, 17 abr. 1936). La frustración del público se centraba no solo en el gobierno y su ineficacia para lograr que la leche fuera segura y barata, sino en la figura de adulterador, que en la cadena de producción y distribución podía ser cualquiera. Por ejemplo, un lector de diario La Prensa opinó que los adulteradores, ya fueran productores, pasteurizadores, mayoristas o minoristas eran "los enemigos públicos número uno" por "la mortalidad que causaban" en la población (La Encuesta..., 7 oct. 1938).

En este artículo analizaré cómo las autoridades mexicanas lucharon por regular el mercado de la leche con el fin de aumentar la oferta y la higiene del producto. Este proceso, que tuvo su auge desde 1902 hasta la década de 1950, se caracterizó por amargas disputas entre el gobierno y todos los actores involucrados en el mercado de la leche (productores, distribuidores, vendedores y pasteurizadores). La anarquía en el mercado de la leche sirvió de excusa para que el gobierno interviniera no solo en el campo sanitario sino también como actor económico. Los productores de leche resistieron las políticas del Estado mexicano argumentando que éstas limitaban su libertad económica, mientras que los vendedores y distribuidores de leche usaron su identidad de clase y afiliación con el movimiento sindical para posicionarse como actores legítimos en el negocio. El gobierno mexicano trató de legitimar su autoridad enfatizando la importancia nutricional de la leche y el peso de la buena salud en general. Asimismo, las autoridades sanitarias invocaron nociones paternalistas sobre la responsabilidad del Estado de proteger a los consumidores de bajos recursos frente a los abusos de los acaparadores y especuladores en el mercado alimenticio. Sin embargo, ni la Secretaría de Salud ni el gobierno de la ciudad tuvo la capacidad administrativa para garantizar un suministro de leche fresca, asequible y limpia. Las agencias alimentarias del gobierno encontraron una salida a la crisis del mercado de la leche fresca impulsando la venta y distribución de leche en polvo reconstituida, un producto que se volvió muy barato y abundante en el ámbito internacional después de la Segunda Guerra Mundial. Finalmente el gobierno solidificó su autoridad reguladora frente a productores y distribuidores logrando así mayor estabilidad en el mercado de leche después de una emergencia sanitaria, la epidemia de fiebre aftosa de 1946.

Los estudios sobre la leche y el papel del Estado como órgano regulador de la salud pública forman parte de una tradición historiográfica más amplia sobre los procesos de configuración de los mercados de los alimentos y bienes de consumo. Melanie DuPuis (2002) argumenta que la universalización del consumo de la leche en los EEUU no se debió a sus características nutricionales ni a que realmente es "el alimento perfecto de la naturaleza", sino a la re-organización de las prácticas en la crianza de los niños, a la urbanización, así como a cambios en la tecnología y al conocimiento experto. En América Latina, la literatura sobre los sistemas alimentarios demuestra que la capacidad del Estado de asegurar el abasto en las ciudades ha sido un elemento crucial de su legitimidad política. Distintos gobiernos 
en la región han utilizado selectivamente políticas paternalistas para tratar de asegurar un piso mínimo de consumo de los productos básicos o aminorar el descontento o movilización social con motivo de la escasez o inflación. El discurso de la lucha contra especuladores, agiotistas, monopolistas, adulteradores y defraudadores ha sido una herramienta que los estados latinoamericanos han utilizado para justificar un rol más activo en la economía (Graham, 2010; Elena, 2011; Weis, 2012). Los gobiernos implementaron políticas con el propósito no solo de proteger las ganancias de los productores sino de favorecer el bienestar de los consumidores. Sin embargo, la literatura sobre la transformación de los mercados alimentarios en la región demuestra que los intereses de los productores y los consumidores son contradictorios y no necesariamente es posible protegerlos al mismo tiempo y usando las mismas herramientas de política económica.

Estudiar el proceso de formalización del mercado de la leche incorpora el factor de los riesgos sanitarios a las discusiones sobre regulación estatal de los alimentos: ¿Qué intereses se favorecen y se negocian cuando pasa a ser obligación del Estado proteger la salud pública? En el caso de la leche en la capital mexicana, el Estado fue al mismo tiempo antagonista y protector de los intereses privados, dependiendo de las circunstancias políticas. Asimismo, siempre le fue más fácil hacer cumplir la regulación sanitaria cuando contó con la cooperación de los grandes productores o intervino directamente proporcionando créditos y subsidios. Para el gobierno mexicano, las prioridades económicas y políticas, es decir, proteger los precios al consumidor así como evitar el descontento entre los actores involucrados en el negocio, tuvieron prioridad frente a las medidas de salud pública, como la pasteurización y la lucha contra la adulteración.

\section{El mercado de la leche desde el régimen porfiriano hasta el primer periodo postrevolucionario: 1902-1936}

Las razones por las cuales el estado mexicano y otros actores como médicos, periodistas e intelectuales comenzaron a considerar la leche como un alimento básico, sobre todo para los niños, tiene que ver no solo con descubrimientos en el campo científico de la nutrición humana, sino con prejuicios sobre la superioridad inherente a las dietas europeas. A finales de siglo XIX y principios del XX, el eurocentrismo y la eugenesia influenciaron las discusiones sobre la alimentación y nutrición en América Latina (Pilcher, 1998; AguilarRodríguez, 2011). En el caso de México, al igual que en otros países de la región, las élites y los médicos comenzaron a incentivar el consumo de leche a través de varias instituciones privadas así como iniciativas públicas para regular la calidad del producto (Barquera, Rivera, Gasca, 2001).

Los primeros esfuerzos por regular los aspectos sanitarios del comercio de la leche en México se produjeron entre 1880 y 1910, cuando el dictador Porfirio Díaz y sus colaboradores se interesaron por modernizar la capital. Con este propósito, médicos e ingenieros afiliados al Consejo Superior de Salubridad recomendaron una serie de reformas y obras públicas para mejorar las condiciones sanitarias de la población. El grueso de la oferta de leche en la Ciudad de México durante la época porfiriana lo suministraban pequeños productores urbanos que tenían, como máximo, una docena de vacas. Las mujeres y los hombres ordeñaban sus 
vacas en las calles, en las plazas de la ciudad o en pequeños establos urbanos al aire libre y vendían la leche directamente al público. Los propietarios de pequeños cafés o "tendajones" también vendían leche. Tenían un pequeño establo junto a sus establecimientos comerciales, compraban a los vendedores ambulantes de leche o se asociaban con un vecino que tenía algunas vacas. Las mujeres eran mayoría entre los productores marginales que vendían leche en la calle (Informe..., 16 ene. 1902). Algunas de ellas producían pan dulce casero o bizcochos y los vendían con la leche. Los grandes productores estaban fuera de los límites de la ciudad, en diferentes distritos y solían contratar o vender la leche a distribuidores que hacían entregas a domicilio. Había una diferencia de consumo por clase social. Los habitantes urbanos de bajos recursos compraban la leche directamente en la calle o en pequeñas tiendas. Los consumidores más ricos enviaban a sus sirvientes por la leche, o recibían envíos directos a sus casas de las grandes granjas lecheras suburbanas (Informe..., 16 ene. 1902). En 1902, el ayuntamiento de la ciudad decidió presionar al Consejo Superior de Salubridad para que les proporcionara un código más específico para regular el comercio de la leche dentro de la ciudad. Los funcionarios del gobierno municipal querían que los vendedores evacuaran las calles y ordeñaran sus vacas en el interior de sus casas o establos, pero no podían obligarlos porque los vendedores de leche no violaban ningún artículo específico del código sanitario. El Consejo sugirió revocar las licencias de venta de leche en la ciudad y prometió contratar a un médico veterinario que inspeccionara las instalaciones de ordeña (Informe..., 16 ene. 1902). La Comisión de Alimentos y Bebidas del Consejo rápidamente comenzó a trabajar en un nuevo código sobre la seguridad de la leche. Finalmente, un nuevo código fue aprobado en 1902 (Secretario..., 30 ene. 1902). El código prohibía los vendedores ambulantes de leche e imponía la venta obligatoria de leche en establos o tiendas que estuvieran "limpias, ventiladas y lejos de los dormitorios o las viviendas de los enfermos" (Prescripciones..., 30 ene. 1902).

Los pequeños y grandes productores y las lecherías respondieron a la ley inicial y a su aplicación de diferentes maneras, que reflejaba su peso relativo en el mercado. Cuanto más débiles eran, más tendían a resistirse. Sin embargo, las medidas del gobierno fueron en parte exitosas ya que 180 vendedores se registraron y pagaron la cuota. Sin embargo, era difícil de determinar para las autoridades el número exacto de personas que producían y vendían leche en la ciudad, dado que algunos de los permisos eran expedidos por las prefecturas de otras localidades (Informe..., 23 feb. 1903). Aunque la ciudad había prohibido a los vendedores ambulantes, los propietarios de establecimientos permanentes se quejaban constantemente de que la leche se vendía en carritos en las dos avenidas más grandes del centro de la ciudad - Chapultepec y Balderas (Gutiérrez, González, González, 14 ago. 1905).

La revolución de 1910 causó una disrupción en el mercado de la leche como lo hizo con la mayoría de las actividades económicas y políticas en el centro de México. El control de precios y la regulación del acceso a los bienes de consumo y agrícolas se estableció durante la lucha revolucionaria como medio para que los diferentes ejércitos alimentaran a sus tropas, mantuvieran el control del suministro en las ciudades y evitaran el hambre. La escasez de alimentos, incluyendo la leche, durante la guerra fue el resultado del desmembramiento del sistema monetario porfiriano, la perturbación de la producción agrícola y la confiscación del sistema de transporte con fines militares (Rodríguez Kuri, 2000). El control de precios 
de la canasta básica, que incluía la leche, continuó después de terminada la revolución y se mantuvo hasta el desmantelamiento del sistema autoritario de partido único y la restructuración económica que ocurrió en la década de 1990.

Una vez pasados los años más álgidos del conflicto armado, las autoridades sanitarias federales retomaron los esfuerzos por regular la calidad de la leche en la capital mexicana. El 29 de diciembre de 1925 se publicó en el Diario Oficial el Código de la Leche. Este código determinaba que en la ciudad se podían vender dos tipos de leche: la pasteurizada y la certificada. Aunque la última no necesitaba ser pasteurizada, los productores debían mantener condiciones de higiene muy estrictas en sus establos. Las autoridades sanitarias debían encargarse de asegurar que el establo estuviera limpio, que el personal ordeñara las vacas en condiciones sanitarias adecuadas y que la leche se entregara al público en botellas limpias (México, 29 dic. 1925).

Cuatro años después de aprobado el código, las autoridades sanitarias federales y de la ciudad se reunieron a discutir cómo todavía la falta de higiene de la leche ponía en peligro al público y lo hacía más susceptible a enfermedades de distintos grados de severidad (Reunión..., 8 oct. 1929). Desde el advenimiento de la teoría microbiana de la enfermedad se sabe que consumir leche sin pasteurizar incrementa los riesgos de contraer diversas enfermedades, entre ellas tuberculosis y brucelosis. Así pues, los médicos insistían que aún la leche pasteurizada se podía contaminar fácilmente, causando fiebre y diarrea. La conclusión de la reunión fue que el gobierno debía continuar trabajando con todos los actores involucrados en el negocio para que la leche dejara de ser peligrosa para la salud.

Las autoridades mexicanas estaban preocupadas no solo por la calidad de la leche sino también por su precio. En 1925, además del Código de la Leche el gobierno de la ciudad creó un Consejo de Regulación a cargo del comercio y consumo de la leche (Oficial..., 20 ago. 1925; Contralor..., 21 ago. 1925). El Consejo estableció los precios oficiales y encargó un estudio para determinar cómo afectaría a los vendedores y productores. A diferencia de las juntas reguladoras de otros productos alimenticios, el Departamento de Salud se hacía cargo de la leche, debido a su naturaleza altamente perecedera. Los miembros de la junta reguladora recopilaron información acerca de los productores de leche que llegaba a la ciudad desde otros estados y de los administradores de las plantas de pasteurización (Miembros..., 23 mar. 1926).

Durante el decenio de 1920, las diferentes actividades relacionadas con el negocio de la leche estaban muy fragmentadas. Distintos grupos se encargaban de la producción, la pasteurización, la distribución y la venta. Como el gobierno establecía los precios, el mercado de la leche se volvió muy conflictivo porque la ganancia de un sector significaba pérdidas para los otros. Los productores que no controlaban los puntos de venta (tiendas de leche o lecherías) solían vender su producto a mayoristas que distribuían la leche por toda la ciudad. Los mayoristas también vendían la leche a las plantas de pasteurización o a pequeñas tiendas de leche. Los productores, mayoristas y dueños de tiendas que compraban y vendían la leche entre ellos trataban de obtener el mejor precio posible (Miembros..., 23 mar. 1926). Los mayoristas compraban la leche a precios baratos, sabiendo que las pequeñas lecherías podrían negarse a comprar leche muy cara. Los precios en las lecherías, es decir, el precio al consumidor final, estaban más regulados que los precios de los productores o 
mayoristas (Miembros..., 23 mar. 1926). La mayoría de los propietarios de establos estaban ubicados relativamente lejos del centro de la ciudad, por lo que dependían de las tiendas de leche o de la entrega a domicilio para vender su producto.

Todos los grupos involucrados en el negocio de la leche apelaban a la intervención gubernamental para proteger sus intereses. Por ejemplo, en 1925 una organización de productores pidió ayuda a la Secretaría de Salud para suprimir a los intermediarios y contratistas. Los ganaderos se quejaban de que las complicidades entre los mayoristas (que tenían licencias para introducir la leche en la ciudad), los propietarios de las plantas de pasteurización y los dueños de lecherías tenían el efecto de reducir sus ganancias. La organización de productores pidió que se cerraran quinientas lecherías no afiliadas y que se redujera el número de plantas de pasteurización. Pero la Secretaría de Salud no estaba dispuesta a cumplir con las exigencias de los productores, alegando que cualquier intervención podría obstaculizar la libertad de comercio (Memorando..., mayo 1928).

En 1926, estos mismos productores se reorganizaron en la Sociedad Regional de Crédito Agrario de Productores de Leche (SRCAPL). Los objetivos de la sociedad eran: obtener créditos, organizar compras en grupo, registrar al ganado y crear departamentos de industrialización y ventas (Banco..., mayo 1928). Los miembros de la sociedad también propusieron que el Código de la Leche clasificara la leche de manera más estricta, utilizando otros estándares de recuento bacteriano, contenido graso y la acidez del producto. Para la SRCALP, la leche certificada era poco fiable y costosa, porque los inspectores del gobierno no podían dar certeza sobre la salud de todas las vacas productoras (Banco..., mayo 1928).

En 1930 el economista Gonzalo Robles, entonces gerente del Banco Nacional de Crédito Agrícola (BNCA), escribió un informe sobre las actividades y las vicisitudes de la SRCAPL que ilustra los retos de la actividad lechera. De acuerdo con Robles, en mayo de 1928 la SRCAPL logró reunir a más de la mitad de los productores (350 ganaderos quienes producían el 50\% del suministro de leche de la capital). La SRCAPL recibió un préstamo de un millón de pesos del BNCA y así los socios pudieron adquirir plantas de pasteurización, lecherías y cubrir los gastos de producción. Sin embargo, la SRCAPL empezó a perder dinero por malas decisiones comerciales, como la compra de plantas y lecherías a un precio más alto que su costo real. Asimismo, los intermediarios y productores no afiliados a la SRCAPL iniciaron una "guerra de precios" negándose a comprar leche o adulterándola con agua para bajar los precios (Romo, Robles, 17 mar. 1930). Después de varias intervenciones para evitar pérdidas, el BNCA pidió al gobierno federal que disolviera la SRCAPL. El gobierno decidió, en cambio, salvar a la sociedad, esperando que las autoridades sanitarias controlaran la adulteración y el fraude. De acuerdo con Robles, esto no ocurrió y la SRCALP se endeudó más con el banco. El BNCA por su parte compraba la leche a la SRCAPL a precios fijos y la vendía en la capital con pérdida (Romo, Robles, 17 mar. 1930). En otro informe gubernamental sobre el mercado de la leche, también de 1930, el autor argumentaba, al igual que Robles, que el gobierno federal debía centralizar la producción, procesamiento y pasteurización para terminar con las "guerras de la leche" que bajaban los precios sin necesariamente aumentar la producción o la calidad del producto. El informe concluyó diciendo que, "contrariando la creencia general de que toda competencia es benéfica para el público consumidor", el "libre mercado de la leche" terminaba perjudicando a los compradores y la salud pública (Memorándum..., 17 mar. 1930). 
Estas propuestas de intervención federal no se materializaron y, en la década de 1930, la SRCAPL siguió disputándose el control del mercado de la leche con mayoristas, pasteurizadores, pequeños vendedores, repartidores, además del Sindicato de Trabajadores de la Industria Lechera de la Ciudad de México (STIL). La SRCALP quería que los mayoristas dejaran de introducir leche de los estados vecinos que venía de productores que no eran miembros de su sociedad. La leche "clandestina" se transportaba sin refrigeración, por lo que era necesario añadir algunas sustancias para que no se agriara durante el viaje. Los mayoristas afirmaban que esa leche era segura pues se pasteurizaba cuando llegaba a la ciudad (Leche, 16 mar. 1931). Las autoridades sanitarias parecían no tener control alguno sobre esta leche, la cual se comercializaba como leche certificada o pasteurizada sin serlo. La SRCALP convenció al Departamento de Salud de que emitiera un decreto en enero de 1931 para enfrentar el problema de la introducción de leche foránea y asegurar la calidad del producto. El decreto establecía que la leche vendida en la ciudad debía ser pasteurizada dentro de los límites de la misma (Leche, 16 mar. 1931).

El decreto de 1931 propició un nuevo debate entre los actores que participaban en el mercado de la leche sobre qué tipo de medidas de salud pública podía usarse para limitar o regular legítimamente el libre comercio. Los productores, las plantas de pasteurización y los propietarios de lecherías comenzaron a acusarse mutuamente en la prensa o en reuniones gubernamentales de intentar monopolizar el mercado. Cada uno de los bandos alegaba que estaba defendiendo sus derechos estipulados en el artículo 28 de la Constitución (México, 1994, p.38). El problema era que este artículo tenía una naturaleza contradictoria. Tuvo su origen en la Constitución de 1847, pero las enmiendas realizadas por los legisladores en 1917 y las regulaciones posteriores derivadas de las enmiendas no siguieron los principios del liberalismo clásico, sino que favorecieron la protección de los intereses sociales por encima de los individuales. El propósito del artículo no era prohibir los monopolios para proteger la libertad comercial ilimitada, sino proteger al público o a una clase social particular (Huerta Reyes, 1947, p.64). No obstante, el sustento de diversos grupos de trabajadores y de pequeños intereses comerciales dependía de los intermediarios del comercio de la leche, en particular de los propietarios de las lecherías y de los repartidores independientes, que formaban, junto con los mayoristas, la Unión de Mayoristas y Repartidores (mayoristas) (La Cooperativa..., 9 nov. 1934). Además, los trabajadores de las tiendas de leche, los choferes y los trabajadores de las plantas de procesamiento de leche, en su mayoría afiliados al STIL, tenían una representación significativa dentro de la organización sindical más grande del centro de México, la Confederación Regional de Obreros y Campesinos (CROC), afiliada al partido en el poder, el Partido Nacional Revolucionario (PNR) (La resolución..., 9 nov. 1934). Por lo tanto, la disputa sobre la naturaleza de las prácticas monopólicas y el artículo 28 fue tanto un problema político como jurídico.

Para 1934, la SRCALP había desaparecido, pero un gran número de productores de la capital se asociaron nuevamente en una empresa llamada Leche y sus Derivados S.A. (Rosales, 28 ene. 1935). El STIL tuvo numerosas disputas con los grupos de mayoristas que manejaban la leche de la capital así como con Leche y sus Derivados. En 1934, el STIL organizó una serie de huelgas contra los mayoristas quienes supuestamente se habían negado a pagarles el salario mínimo estipulado (Sáenz, 30 oct. 1934). Los miembros se 
reunieron con Áaron Sáenz, jefe de gobierno de la capital, y le pidieron apoyo para formar una cooperativa lechera. Los trabajadores afirmaron que el problema de la industria lechera en su conjunto no se resolvería "hasta que los trabajadores se apropiaran de los medios de producción" (Sáenz, 30 oct. 1934). Los mayoristas reaccionaron montando una campaña mediática contra el sindicato y la empresa de productores de Leche y sus Derivados. En un editorial del diario La Prensa, el autor acusó a los productores de querer subir el precio de la leche usando el pretexto de que sería la única forma de evitar la adulteración. Según el editorialista, los pequeños productores, cuya leche se entregaba directamente a los mayoristas, acusaban a Leche y sus Derivados de adulterar leche en sus establos (El monopolio..., 1 ene. 1934). También los mayoristas afirmaban que la empresa era un "trust lechero" y una "mafia capitalista" que quería eliminar "a los pequeños mayoristas de origen obrero" (El Sindicato..., 5 nov. 1934; La cooperativa..., 9 nov. 1934). La Prensa informó que un numeroso grupo de repartidores y vendedores visitaron su sede acusando a "un grupo de extranjeros" de formar un monopolio para arruinarlos. Por su parte, Excélsior y La Prensa informaron que repartidores y vendedores fueron a sus oficinas para acusar a Leche y sus Derivados de tirar treinta mil litros de leche al día para encarecer la leche y expulsarlos del mercado (Se pretende..., 4 nov. 1934; Otro monopolio..., 4 nov. 1934). Leche y sus Derivados emitió inmediatamente un manifiesto en el que se identificaba como una organización de productores, que se oponía a las prácticas monopolísticas. Según el manifiesto los mayoristas, sus rivales, eran los intermediarios y los especuladores (Leche y..., 11 nov. 1934).

Mientras tanto el gobierno mexicano mostró poca voluntad para mediar en el conflicto lechero y asegurarse de que el producto fuera seguro para el consumo humano. Los periódicos reportaban que aún después de la reforma al código sanitario, en 1931, la cantidad de leches "aguadas, descremadas, alteradas y adulteradas" que se vendían al público y "provocaban enfermedades en los niños" eran "aterradoras" (La leche..., 4 mar. 1932). Dada la constante mala prensa, los miembros del Departamento de Salud Pública redoblaron sus esfuerzos para controlar la adulteración. Sin embargo, no tuvieron éxito porque los funcionarios de alto rango ni siquiera tenían demasiada injerencia sobre sus propios inspectores. Por ejemplo, Salvador Zubirán, jefe del Servicio de Alimentos y Bebidas, había recomendado que el Departamento investigara a ocho agentes a su cargo porque había recibido numerosas quejas de mal comportamiento. Sospechaba que los agentes escribían informes falsos, extorsionaban a los vendedores en los mercados públicos y no hacían evaluaciones honestas de las plantas de pasteurización de leche. Sin embargo, el servicio jurídico del Departamento no podía dar a los inspectores ninguna sanción administrativa ni expulsarlos dadas sus conexiones políticas (Melo, 2 mar. 1932).

Debido a las numerosas acusaciones de corrupción en 1935, los funcionarios del Departamento de Salud encargaron un estudio sobre la adulteración de la leche en la ciudad. El estudio sugería una vez más que la solución era la centralización del procesamiento y de la producción. El gobierno propuso dar derechos exclusivos a los productores de Leche y sus Derivados durante veinte años con la condición de que el grupo no se organizara como una empresa privada. El gobierno quería que Leche y sus Derivados fuera una empresa mixta que incluyera intereses públicos. La Secretaría de Economía determinaría los parámetros para 
que la empresa pudiera llevar a cabo su administración. Luego los funcionarios decretarían el nivel exacto de capitalización y los máximos beneficios permitidos. Los socios de Leche y sus Derivados estarían obligados a distribuir el 10\% de su leche en los barrios de gente pobre a un precio accesible (Memorándum..., 28 ene. 1935). Los funcionarios de la Jefatura de Estudios Económicos escribieron lo siguiente:

La gente que quiere que el mercado de leche mexicano permanezca en el caos responde a ... una ideología que defiende una noción altamente individualista de darwinismo social desenfrenado y asume la pasividad del estado ante los esfuerzos de individuos poco éticos que quieren explotar a otros y beneficiarse de ellos. Ponen toda su fe en la competencia no regulada y olvidan que la competencia desleal es un hecho inmutable (Jefatura..., 1935).

El presidente de Leche y sus Derivados apoyó la moción y declaró que la empresa podría tener éxito donde las autoridades sanitarias habían fracasado e imponer orden en el mercado de la leche así como "el presidente de México había ordenado" (Memorándum..., 28 ene.1935).

Sin embargo, el crecimiento demográfico y la demanda de leche en la capital así como el apoyo del gobierno a Leche y sus Derivados afectaron a los productores de otras tres ciudades del centro de México: Toluca, Tehuacán y Veracruz. Los productores situados más cerca de la capital, en el estado de México, estaban preocupados de que Leche y sus Derivados obtuviera una concesión del gobierno para dirigir la única planta de pasteurización de la ciudad. Los miembros de la Unión de Ganaderos de Toluca se opusieron a la creación de la empresa y enviaron cartas a los periódicos. Apelaron a los consumidores, explicando que el proyecto también incluía el aumento de los precios de la leche certificada y pasteurizada (Reglamento..., 15 jun. 1935). En las ciudades más grandes del estado de Puebla, el problema era que la leche era escasa y cara pues parte de su producción se desviaba al mercado de la Ciudad de México. Los productores de Puebla también siguieron la estrategia de Leche y sus Derivados, creando cooperativas de productores, la cual causó un gran rechazo entre los consumidores. Un grupo de ciudadanos de la ciudad de Tehuacán, Puebla, organizó una Liga de Resistencia del Consumidor y, basándose en el artículo 28 de la Constitución, convocó a una huelga de consumidores de leche. La Liga se quejó que la leche de la cooperativa era descremada, supuestamente perdiendo todas sus propiedades nutricionales y, además, costaba el doble (Manifiesto..., 31 jul. 1935). Los quinientos miembros de la Liga se reunieron en el ayuntamiento, asaltaron la lechería y vertieron en las alcantarillas toda la leche que encontraron. Después del altercado, los precios volvieron a bajar pero algunos de los consumidores dudaban que su protesta tuviera efectos reales a largo plazo en los precios (Liga..., 3 ago. 1935).

También en 1935, el puerto de Veracruz hizo obligatoria la pasteurización y permitió la apertura de una planta única para este propósito. En un año ambas políticas fracasaron. Primero, los dueños de la planta única se resistieron al control de precios y dejaron a la ciudad sin leche durante un par de días, argumentando que no les resultaba rentable vender el producto (Los veracruzanos..., 18 dic. 1935; Huelga..., 3 nov. 1936). Enseguida las autoridades municipales, junto con grupos de trabajadores, organizaron un boicot contra la 
leche pasteurizada. Para contrarrestar la escasez de leche, la ciudad volvió a legalizar la venta de leche no pasteurizada (Amenaza..., 23 feb. 1936; Boicot..., 22 feb. 1936; Contra..., 20 feb. 1936; Lleva..., 26 feb. 1936; Sigue..., 25 feb. 1936). Algunos ganaderos que vendían leche no pasteurizada se quejaron de que aunque su actividad era legal, seguían siendo acosados por las autoridades y por la cooperativa lechera propietaria de la planta de pasteurización. El conflicto duró meses y la gente se manifestó en las calles contra el alza de precios y la mala calidad de la leche. Una de las manifestaciones, organizada por un sindicato de trabajadores, se tornó violenta y los manifestantes destruyeron la planta (Destrucción..., 3 mar. 1936). Un columnista de un periódico de la Ciudad de México reconoció que la acción era simbólica, en el sentido de que "el pueblo de México" no estaba en contra de "la ciencia de Pasteur" sino que estaba cansado de ser estafado por "capitalistas que utilizaban la tecnología para crear monopolios" y que ni siquiera vendían leche de alta calidad (Labra, 18 dic. 1936). Unos días más tarde, los periódicos informaron que se normalizaba la venta de leche pasteurizada y no pasteurizada en el puerto (La planta..., 3 mar. 1936). Para la prensa el experimento de hacer obligatoria la pasteurización en Veracruz fue un ejemplo de los conflictos que podrían ocurrir si el gobierno implementaba esta misma medida en la capital del país.

\section{La inflación, la movilización de los trabajadores y el mercado de la leche: 1936-1946}

A finales de la década de 1930, la presión inflacionaria provocó enormes pérdidas para los productores lecheros. Parte de los problemas financieros eran debido a que el costo del alimento para ganado, especialmente el heno y la alfalfa, aumentaba constantemente. Mientras tanto, el gobierno continuó fijando los precios de la canasta básica que incluía la leche. Esta situación generó más tensiones entre el gobierno y los productores de leche, porque aunque oficialmente los precios del alimento para ganado también estaban regulados, los productores afirmaban que en realidad los precios seguían aumentando. La crisis económica además coincidió con un período de sequías. Estos dos factores fueron desastrosos para la producción agrícola en general. La crisis de producción se agravó debido al ambicioso plan de reforma agraria y distribución de tierras de la administración del presidente Lázaro Cárdenas (1934-1940). Los bancos privados y la mayoría de los inversores, quienes no apoyaban las políticas distributivas de Cárdenas, no estaban dispuestos a prestar dinero a los productores agrícolas. El gobierno continuó fijando los precios de los productos básicos con la esperanza de parar la espiral inflacionaria (Beteta, 1951, p.10-15). Así pues, la mayoría de los productores de leche se vieron atrapados en una situación en la que sus costes eran más altos que sus beneficios, y en el caso de la empresa Leche y Sus Derivados esto la llevó a la quiebra (Leche..., 2 jul. 1937).

Otro factor que afectó la situación del mercado de la leche en la capital fue el aumento de la movilización laboral durante la presidencia de Cárdenas. La mayoría de los pequeños propietarios de tiendas de leche, repartidores y trabajadores de las plantas de pasteurización tenían sus propias organizaciones de trabajadores, que a su vez pertenecían a sindicatos más grandes como la Confederación de Trabajadores de México (CTM). De 1936 a 1939, los trabajadores de las plantas de pasteurización se embarcaron en una 
serie de huelgas que con frecuencia paralizaban la producción. Otros tipos de activismo obrero también afectaron el funcionamiento de las plantas de la capital. En agosto de 1936, los trabajadores de la empresa Mexican Light, que suministraba electricidad a la mayor parte del centro de México, se declararon en huelga, lo que provocó la suspensión del servicio durante varias semanas. Durante la huelga, los propietarios de las plantas de pasteurización declararon que no podían cumplir las leyes sanitarias si no había energía disponible (Campa, 1978, p.122-123). Ese mismo año, un senador le mandó una carta al presidente Cárdenas proponiéndole encabezar una campaña en el cuerpo legislativo para proponer nuevamente la creación de una única planta de pasteurización en la ciudad para bajar los precios (Armendáriz del Castillo, 10 jul. 1936). El departamento de salubridad y la CTM también hicieron declaraciones a la prensa apoyando el proyecto de la planta pasteurizadora única (El control..., 8 ene. 1936; Solicitan..., 7 sep. 1937). Un año más tarde, en 1937, el gobierno de Cárdenas emitió un decreto que otorgaba la concesión de la planta a los trabajadores de la leche rafiliados al sindicato. Se suponía que los trabajadores iban a construir y dirigir la planta, pero este proyecto primero se retrasó y luego nunca se llevó a cabo (Dueña..., 23 jun. 1938; La solución..., 4 ene. 1938). El 18 de mayo de 1938, Cárdenas nacionalizó la industria petrolera, por lo que fue un momento desfavorable para que el gobierno encabezara otro proyecto que seguramente causaría más conflictos con el sector privado.

Un nuevo gobierno, que tomó posesión en 1941, mostró un renovado interés en reorganizar el mercado de la leche en la ciudad y, finalmente, en hacer cumplir todas las normas sanitarias. El nuevo jefe de los servicios sanitarios de la capital, Víctor Fernández, dio mucha publicidad en los periódicos a su campaña contra la adulteración. Los diarios imprimieron las direcciones de los establecimientos multados y los nombres de los propietarios. El jefe de los servicios sanitarios exhortó a los particulares a escribir a las autoridades y a denunciar cualquier violación del Código de la Leche (La leche..., 29 mayo 1941; Medidas..., 3 jun. 1941; Los de..., 5 jun. 1941). La estrategia funcionó y ese año los residentes de distintos barrios de la ciudad, especialmente del centro, escribieron a las autoridades denunciando establos clandestinos o adulteradores de leche (Telegramas..., nov. 1941). El jefe del Departamento de Salubridad Pública también acordó con la CTM vigilar a los expendedores de leche y hacer que suprimir la adulteración de la leche se volviera de "índole educacional y moral" para los trabajadores (Habrá..., 1 jun. 1941).

Sin embargo, dos años después estalló un escándalo en relación con la participación de destacados dirigentes obreros de la CTM y la Confederación de Trabajadores del Distrito Federal (CTDF) en prácticas monopólicas. Estas dos organizaciones contaban entre sus filas a cinco mil personas que se ganaban la vida en actividades relacionadas con la producción y venta de leche. Sin embargo, había tensiones entre el liderazgo de los sindicatos y las bases asociadas a la industria lechera. Los dirigentes de la CTM y la CTDF querían establecer un límite a las ganancias de todas las transacciones relacionadas con la venta de leche, un decreto que afectaría a los propietarios de las lecherías y a los repartidores (Denuncian..., 29 jul. 1943; Líderes de..., 22 oct. 1943; Grave acusación..., 27 oct. 1943). En octubre de 1943, el periódico La Prensa informó sobre una acalorada discusión durante una reunión de trabajadores de la CTM y la CTDF. Varios lecheros y vendedores de leche comenzaron 
a acusar a destacados dirigentes de la CTM, como Vicente Lombardo Toledano y Fidel Velázquez, de estar aliados con los propietarios de las plantas de pasteurización. Los repartidores de leche se quejaron de que la CTM y el partido oficial, el PRM, querían echarlos del negocio (Unión..., 2 oct. 1943). Los dirigentes de la CTM negaron públicamente las acusaciones de La Prensa (Desmiente..., 12 dic. 1943). El periódico continuó publicando historias e informó que en realidad Lombardo era el dueño de una planta de pasteurización y que varios políticos, incluyendo miembros del Congreso, estaban involucrados en la adulteración de la leche. Según el periódico, estos dirigentes sindicales habían conseguido contratos públicos con hospitales e instituciones públicas y vendían la leche a precios más altos que los permitidos por la ley (Quiénes..., 13 dic. 1943).

Los problemas entre propietarios de las plantas de pasteurización y los dueños de las lecherías y repartidores continuaron durante los meses siguientes. En diciembre de 1943, las plantas de pasteurización dejaron de vender leche a dos mil lecherías de la ciudad. Los periódicos afirmaron que era una estrategia de las plantas para crear una escasez artificial y obligar a las autoridades a aumentar el precio oficial de la leche. La Secretaría de Salud declaró públicamente que la escasez de leche era real y que se debía al carácter estacional de la producción, que tendía a disminuir durante los meses de invierno (Denigri, 23 dic. 1943; Otro esfuerzo..., 27 ene. 1944). Pero la escasez no sólo se debía a este carácter estacional, sino que también se originaba en la participación de México en la Segunda Guerra Mundial, que comenzó oficialmente en junio de 1942. La guerra interrumpió el sistema de producción y distribución de alimentos de México. El mercado de la leche se vio afectado por la guerra porque los precios de los pastos y de los alimentos para animales volvieron a subir considerablemente (Ochoa, 1999).

En 1945, el presidente Manuel Ávila Camacho le encargó a Francisco Doria Paz, representante de la industria ante el Consejo de Precios de la ciudad, que hiciera recomendaciones al ejecutivo sobre la leche. Doria Paz colaboró estrechamente con técnicos norteamericanos especializados en problemas lácteos. En su opinión, los establos mexicanos no podían abastecer permanentemente a la ciudad debido a la falta de ganado de raza pura y a un suministro muy limitado de pastos y otros alimentos. Los asesores norteamericanos recomendaron la instalación de una planta que rehidratara leche en polvo importada, gestionada por el gobierno. El presidente, cuya política era no interferir en la producción industrial privada, ordenó al gobierno de la capital que tratara de convencer a algún inversor para que construyera una planta, ofreciendo exenciones fiscales como incentivos (Hurtado Alvarado, 28 ene. 1947). El Poder Ejecutivo también negoció con el gobierno de los EEUU, que aceptó subvencionar la importación de leche en polvo a México. En ese momento los EEUU producía un gran excedente de leche en polvo y buscaban un mercado. El gobierno de este país consideró que permitir que la transacción tuviera lugar sin aranceles era una medida amistosa muy efectiva hacia México, un aliado durante la guerra. Los principales beneficiarios del acuerdo fueron las empresas importadoras (Kraft Foods) y una planta de rehidratación y pasteurización de propiedad mexicana llamada Lechería Nacional (Hurtado Alvarado, 28 ene. 1947).

En octubre de 1945 se estableció la sociedad anónima llamada Lechería Nacional. La empresa firmó un contrato con Kraft Foods Company, a la que la Lechería Nacional le 
compró toda la leche que iba a ser utilizada en la planta. El primer objetivo de los inversores era que la planta produjera un máximo de quinientos mil litros mensuales durante los primeros seis meses de funcionamiento (Hurtado Alvarado, 28 ene. 1947). El presidente mexicano, en un acuerdo colectivo con el secretario de Hacienda, el regente de la capital y el secretario de Economía, decidió otorgar a la Lechería Nacional un subsidio equivalente al monto de los impuestos a la importación de maquinaria, equipo y materias primas. Las autoridades también declararon a la planta rehidratadora propiedad de la Lechería Nacional como una "industria necesaria" para la Ciudad de México. Como consecuencia, la corporación no tendría que pagar impuestos locales (Hurtado Alvarado, 28 ene. 1947).

Las organizaciones de productores de leche reaccionaron inmediatamente al plan del gobierno de rehidratar la leche en polvo y venderla en la Ciudad de México. La Organización de Ganaderos del Estado de México, que representaba a todas las organizaciones regionales de productores de las zonas suburbanas de la Ciudad de México, así como la Cámara de Productores de Leche del Distrito Federal y la Granja Unida del Distrito de Coapa, publicaron varias cartas abiertas al presidente en las que protestaban por la injerencia del Estado en el mercado de la leche. Los productores alegaron que a las autoridades de la Ciudad de México ya no les importaba el estado ruinoso del negocio de la leche local porque el país en general recibía enormes cantidades de leche en polvo de los EEUU y Canadá. Los productores también se quejaron de que estas medidas gubernamentales representaban una competencia ilegal, ya que el gobierno iba a vender un producto que difícilmente podía considerarse tan nutritivo como la leche fresca (Cámara..., 27 nov. 1945; Carta..., 15 mayo 1946). Sin embargo, el gobierno no dejó de importar leche y, en los meses siguientes, los productores de leche se verían obligados a desviar su atención hacia una emergencia fitosanitaria.

\section{La producción de leche y la crisis de la fiebre aftosa: 1946-1952}

Inmediatamente después del final de la Segunda Guerra Mundial, México se enfrentó a una epidemia de fiebre aftosa que puso en peligro toda la industria ganadera del país. La fiebre aftosa es una enfermedad viral altamente contagiosa que afecta los animales de pezuña hendida y reduce su tasa de fertilidad y crecimiento. La epidemia duró de 1946 a 1951 y alrededor del 90\% del ganado en el centro del país (en los estados de Veracruz, Hidalgo, Morelos, Guerrero, Tlaxcala, México, Distrito Federal, Guanajuato, Jalisco, Oaxaca, Aguascalientes y Querétaro) se infectó. Además se calcula que de este porcentaje el 80\% murió o fue sacrificado durante el brote. El brote afectó de manera substancial la producción de leche fresca, especialmente aquella que no provenía de ganado especializado (México..., 23 abr. 1947; Urgencia..., 27 jul. 1947; Secretaría de Economía, 1952, p.31).

El gobierno mexicano y el nuevo presidente Miguel Alemán (quien entró en funciones en 1946) organizaron rápidamente una campaña para controlar la enfermedad. Este esfuerzo, consistió en la inspección, el sacrificio del ganado infectado y expuesto, el entierro profundo, la desinfección y la cuarentena. Las medidas se consideraron temporales hasta que se controlara el brote (Aguirre Sánchez, 1969, p.7). La epidemia redujo significativamente la producción de leche y carne y el suministro a las ciudades. El gobierno predijo que habría 
escasez de leche en la Ciudad de México y los otros centros urbanos circundantes (La producción..., 29 dic. 1946).

Varios meses después del brote de fiebre aftosa, el gobierno de Miguel Alemán promovió el consumo de leche en polvo importada de los EEUU a través de la empresa Lechería Nacional, lo que otra vez causó conflicto con los productores locales. La mayoría de los productores de leche de la región se manifestaron en contra de que el gobierno facilitara la importación de lácteos. Los productores exigieron que el gobierno incrementara los impuestos a estos productos y pidieron la suspensión de los anuncios publicitarios de productos lácteos provenientes de EEUU en los medios de comunicación (Unión..., 8 ene. 1947; Productores..., 17 ago. 1947). Ecos de estas demandas se repitieron en pueblos rurales de estados como Guerrero, donde un presidente municipal afirmó que había rumores de que la fiebre aftosa "era una conspiración de los gringos para vender leche en polvo" (Girón Gozález, dic. 1947; Fuentes, 12 ene. 1948). Asimismo, múltiples caricaturas comenzaron a aparecer en los diarios de la Ciudad de México que se referían a la importación de leche en polvo (La caricatura..., 1988, p.23). En particular, el Taller de la Gráfica Popular, integrado por impresores y artistas de izquierda, publicó y distribuyó en las calles una serie de grabados en los que la fiebre aftosa y la leche en polvo importada de EEUU aparecían como los verdugos de la industria lechera y los consumidores mexicanos (Taller de Gráfica Popular, 1949, p.10-15).

De acuerdo a una evaluación técnica comisionada por Miguel Alemán, México importó cuatro millones de kilos de leche entera en polvo en 1946, seis millones en 1947 y tres millones en 1948. Estas cifras no incluían la leche descremada que la Lechería Nacional compró a productores estadounidenses. El memorándum afirmaba que los productores de leche instaban al gobierno a limitar todas las importaciones de leche en polvo porque era ruinoso para su negocio. Sin embargo, el gobierno defendía las importaciones de leche descremada en polvo porque en ese momento este tipo de leche no se podía producir en México, y muchas industrias, como las panaderías, la utilizaban en sus productos (Memorándum..., 19 oct. 1949).

La epidemia no sólo consolidó la creciente intervención del gobierno en el mercado de la leche, sino que hizo que el negocio fuera viable solo para aquellos productores que tenían suficiente capital para invertir. A finales de la década de 1940, los productores de la capital y sus alrededores seguían muy descontentos con la importación de leche en polvo (Subirá..., 2 feb. 1949). Los ganaderos de la Ciudad de México y del estado de México decidieron promover la pasteurización como una forma de autorregularse y formar un frente común ante el gobierno que para competir con su producción importaba leche en polvo. Con este propósito, los propietarios de grandes ranchos privados que poseían de cincuenta a trescientas vacas y plantas privadas de pasteurización, fundaron la Asociación de Productores de Leche Pura (APLP). Los miembros de esta organización afirmaban que ellos eran los únicos productores locales de peso todavía en existencia en el centro de México, pues un gran porcentaje de pequeños productores de leche había desaparecido con la epidemia (Asociación..., 30 ene. 1952). Fuentes oficiales confirman que la epidemia afectó desproporcionadamente a los pequeños propietarios ganaderos. Gran parte de los hogares 
rurales del centro de México que tenían solo unas pocas cabezas de ganado sufrieron la mayor parte de las consecuencias económicas de las políticas sanitarias para controlar la fiebre aftosa (Machado, 1968).

Las autoridades sanitarias establecieron una mejor relación de trabajo con la APLP que con otros grupos de productores en el pasado. La APLP, la Secretaría de Salubridad y la Asociación Mexicana de Puericultura acordaron tratar de cambiar la imagen de la leche fresca entre los médicos, insistiendo que ya no era peligrosa para el público si provenía de productores acreditados (Sánchez Ríos, oct. 1950). La APLP también apoyó a las autoridades sanitarias en contra de las protestas de los pequeños productores, quienes pedían extender el plazo para cumplir con los requisitos de pasteurizar la leche (Asociación..., 30 ene. 1952). Sin embargo, los pequeños establos y la venta de leche no pasteurizada (aunque a escala mucho menor que en la primera mitad del siglo XX) siguieron existiendo hasta 1972, cuando el gobierno del presidente Luis Echeverría implementó un programa para reubicar en estados vecinos a todo el ganado lechero que quedaba en la ciudad (Convenio.., 16 ago. 1976). Un año después, los miembros de APLP se consolidaron en una sola empresa de lácteos (Alpura) para competir con empresas similares, tanto transnacionales (Nestlé) y como del norte de México (Lala) (Mexico..., 4 sep. 1984). Por su parte el gobierno continuó apoyando a la empresa Lechería Nacional y, en la década de 1960, cedió el control del abasto social de leche que tenía esa empresa a la Compañía de las Subsistencias Populares, la agencia alimentaria pública dedicada a mantener estables la oferta y los precios de los productos básicos. El estado desmanteló la mayoría de las paraestatales alimentarias en la década de 1990, excepto Liconsa, la empresa lechera, que aún continua en operación.

\section{Consideraciones finales}

El negocio de la leche fresca en la capital mexicana durante la primera mitad del siglo veinte fue una fuente constante de disputas entre una gran variedad de actores privados y el Estado. En su afán de asegurarse que los consumidores pudieran tomar leche segura y a precios accesibles, el gobierno mexicano dictó las condiciones bajo las cuales operaron los productores, distribuidores y mayoristas. La prioridad en la práctica y en el discurso de los distintos actores fue abiertamente negociar y movilizarse para lograr la aplicación selectiva de las regulaciones, entre ellas la pasteurización. Diversos actores estatales y privados presentaron la centralización del negocio y el establecimiento de una planta de pasteurización única como la solución al "problema de la leche" pero estas acciones nunca se concretaron. Finalmente, después de décadas de resistencia por parte de los actores de menor peso económico, el negocio se centralizó tanto en manos públicas como privadas. El gobierno solo pudo tener mayor control sobre el precio y la seguridad de la leche importando leche polvo y vendiéndola directamente al público. Los grandes productores pudieron adaptarse al hecho de que el Estado (a través de sus paraestatales) era ahora un competidor. Estos productores optaron por ocupar el nicho de la leche fresca pasteurizada, que podían vender a consumidores de más alto poder adquisitivo, mientras el gobierno se encargó de cubrir las necesidades de los consumidores más pobres. 


\section{REFERENCIAS}

AGUILAR-RODRÍGUEZ, Sandra. Nutrition and modernity: milk consumption in 1940s and 1950s Mexico. Radical History Review, v.2011, n.110, p.36-58, 2011.

AGUIRRE SÁNCHEZ, Alfredo. Contribución a las medidas que deben tomarse para prevenir un brote de fiebre aftosa en México. Ciudad de México: Universidad Nacional Autónoma de México, 1969.

AMENAZA de paro, la cuestión de la leche en Veracruz. El Universal, 23 feb. 1936.

ARMENDÁRIZ DEL CASTILLO, Mariano. Mariano Armendáriz del Castillo a Lázaro Cárdenas, LCR, exp.639, v.521.6/2, 1-3 (Archivo General de la Nación, Ciudad de México). 10 jul. 1936.

ASOCIACIÓN Nacional de Productores de Leche Pura S.A. a Miguel Alemán. MAV, exp.1009, v.368/9868 (Archivo General de la Nación, Ciudad de México). 30 ene. 1952.

BANCO Nacional Crédito Agrícola al Departamento de Salubridad Pública, AHSS, SP, SJ, c.15, exp.5 (Archivo Histórico de la Secretaría de Salud, Ciudad de México). mayo 1928.

BARQUERA Simón; RIVERA Juan; and GASCA Alejandra. Políticas y programas de alimentación y nutrición en México, Salud Pública de México, v.43, n.5, p.465-466, 2001.

BETETA, Ramón. Tres años de política hacendaria, 1947-1948-1949: perspectiva, acción. Ciudad de México: Secretaría de Hacienda y Crédito Público, Publicación de Memorias, 1951.

BOICOT contra el monopolio. El Universal, 22 feb. 1936.

CÁMARA de la Industria y Producción de Leche Autorizada por la Secretaría de la Economía Nacional a Manuel Ávila Camacho, MAC exp.596, v.523.1/26 (Archivo General de la Nación, Ciudad de México). 27 nov. 1945.

CAMPA, Valentín. Mi testimonio: experiencias de un comunista Mexicano. Ciudad de México: Ediciones de Cultura Popular, 1978.

CARTA abierta de la Unión Ganadera Regional del Estado de México, Cámara de la Industria y la Producción de Leche del Distrito Federal y Granjas Unidas de Coapa. Excélsior, 15 mayo 1946.

CERVANTES, Fernando. El problema de la leche. El Universal Gráfico, 17 abr. 1936.

CONTRA el monopolio de leche en Veracruz. $E l$ Día, 20 feb. 1936.
CONTRALOR al jefe del Departamento de Salubridad Pública, SP, SJ c.4, exp.9 (Archivo Histórico de la Secretaría de Salud, Ciudad de México). 21 ago. 1925.

CONVENIO: fideicomiso Fondo del Programa de Descentralización de las Explotaciones Lecheras del Distrito Federal, SSA, Spr C332, exp.2, 5 (Archivo Histórico de la Secretaría de Salud, Ciudad de México). 16 ago. 1976.

DENIGRI, Carlos. Ríos de leche correrán en las calles de nuestra ciudad. Excélsior, 23 dic. 1943.

DENUNCIAN los trabajadores criminal monopolio de la leche. Novedades, 29 jul. 1943.

DESMIENTE una venenosa y lépera calumnia del Diario La Prensa. El Popular, 12 dic. 1943.

DESTRUCCIÓN de la planta pasteurizadora. $E l$ Universal, 3 mar. 1936.

DUEÑA de una planta Industrial amparada. $E l$ Universal, 23 jun. 1938.

DUPUIS, Erna Melanie. Nature's perfect food: how milk became America's drink. New York: New York University Press, 2002.

EL CONTROL de la leche en el Distrito Federal. La Prensa, 8 ene. 1936.

EL MONOPOLIO de la leche, el monopolio del cinismo. La Prensa, 1 ene. 1934.

EL SINDICATO Único de Mayoristas y Repartidores de Leche del DF, adherido a la CGT lanza manifiesto. El Universal, 5 nov. 1934.

ELENA, Eduardo. Dignifying Argentina : peronism, citizenship, and mass consumption. Pittsburgh, PA: University of Pittsburgh Press, 2011.

FUENTES, Pablo. Pablo Fuentes a Miguel Alemán, MAV, exp.291, v.425.5/2-12 (Archivo General de la Nación, Ciudad de México). 12 ene. 1948.

GIRÓN GONZÁLEZ, José I. José I. Girón González a Miguel Alemán, MAV, exp.290, v.425.5/2-11 (Archivo General de la Nación, Ciudad de México). dic. 1947.

GRAHAM, Richard. Feeding the city: from street market to liberal reform in Salvador, Brazil, 17801860. Austin: University of Texas Press, 2010.

GRAVE acusación contra líderes de la CTM. Novedades, 27 oct. 1943.

GUTIÉRREZ, Gerardo; GONZÁLEZ, Santiago; GONZÁLEZ, Albino. Carta al C. Gobernador del DF, Ayuntamiento-Gobierno del Distrito Federal, Lecherías, v.1690 (Archivo Histórico del Distrito Federal, Ciudad de México). 14 ago. 1905. 
HABRÁ cooperación para que se venda leche pura. La Prensa, 1 jun. 1941.

HUELGA contra los lecheros en Veracruz. El Día, 3 nov. 1936.

HUERTA REYES, Antonio. La prohibición del monopolio en el Artículo 28 constitucional y su ley orgánica vigente. Ciudad de México: Universidad Autónoma de México, 1947.

HURTADO ALVARADO, Enrique. Enrique Hurtado Alvarado al jefe del Departamento de Industrias (Actividades de Lechería Nacional), MAV, exp.473, v.513.1/14 (Archivo General de la Nación, Ciudad de México). 28 ene. 1947.

INFORME del ayuntamiento. AyuntamientoGobierno del Distrito Federal, Lecherías, v.1689, exp.27 (Archivo Histórico del Distrito Federal, Ciudad de México). 23 feb. 1903.

INFORME del ayuntamiento de la Ciudad de México. Ayuntamiento-Gobierno del Distrito Federal, Lecherías, v.1687 (Archivo Histórico del Distrito Federal, Ciudad de México). 16 ene. 1902.

JEFATURA de Estudios Económicos. La reglamentación e integración de la industria lechera en el DF y la protesta de los productores clandestinos, SP, SJ, c.43, exp.14 (Archivo Histórico de la Secretaría de Salud, Ciudad de México). 1935.

LA CARICATURA en México. Ciudad de México: Editorial Grijalbo, 1988.

LA COOPERATIVA de lecheros se defiende del capitalista. La Prensa, 9 nov. 1934.

LA ENCUESTA relámpago. La Prensa. 7 oct. 1938.

LA LECHE mala está diezmando a los pequeñuelos. El Día, 4 mar. 1932.

LA LECHE uno de los más activos venenos que ingiere el pueblo. La Prensa, 29 mayo 1941.

LA PLANTA pasteurizadora destruida. $E l$ Universal, 3 mar. 1936.

LA PRODUCCIÓN de leche aumentará. El Universal, 29 dic. 1946.

LA RESOLUCIÓN del embrollo de la leche. $E l$ Universal, 9 nov. 1934.

LA SOLUCIÓN del problema de la leche en el D.F. El Nacional, 4 ene. 1938.

LABRA, Jorge. Inmoralidad y mercantilismo. Excélsior, 18 dic. 1936.

LECHE. Boletín Mensual de la Secretaría de Comercio, p.7-9, 16 mar. 1931.
LECHE pura o se clausuran las pasteurizadoras. El Nacional, 2 jul. 1937.

LECHE y sus Derivados S.A. no es un monopolio. El Universal, 11 nov. 1934.

LÍDERES de la CTM aparecen mezclados en el monopolio de la leche. La Prensa, 22 oct. 1943.

LIGA de consumidores de leche. El Día, 3 ago. 1935.

LLEVA cuatro días el puerto de Veracruz sin leche. El Día, 26 feb. 1936.

LOS DE la vaca y la pata. El Universal, 5 jun. 1941.

LOS VERACRUZANOS se quedaron ayer sin tomar leche. El Universal, 18 dic. 1935.

MACHADO, Manuel. An industry in crisis: Mexican-United States cooperation in the control of foot-and-mouth disease. Berkeley: University of California Press, 1968.

MANIFIESTO de la Liga de Resistencia de Consumidores, LCR, v.639, exp.221.6/21 (Archivo General de la Nación, Ciudad de México). 31 jul. 1935.

MEDIDAS para obtener pureza de la leche. $E l$ Nacional, 3 jun. 1941.

MELO, Gastón. Gastón Melo al jefe de Servicios Jurídicos y Salvador Zubirán, SP, SJ, c.30, exp.22 (Archivo Histórico de la Secretaría de Salud, Ciudad de México). 2 mar. 1932.

MEMORANDO del Departamento de Salubridad Pública. SP, SJ, c.4, exp.9 (Archivo Histórico de la Secretaría de Salud, Ciudad de México). mayo 1928.

MEMORÁNDUM Banco Nacional de Crédito Agrícola. GR, c.34, exp.16 (Archivo General de la Nación, Ciudad de México). 17 mar. 1930.

MEMORÁNDUM relacionado con la importación de México de leche entera en polvo. MAV, exp.569, v.545 (Archivo General de la Nación, Ciudad de México). 19 oct. 1949.

MEMORÁNDUM sobre el mercado de leche en el Distrito Federal. SP, SJ, c.43, exp.14 (Archivo Histórico de la Secretaría de Salud, Ciudad de México). 28 ene. 1935.

MÉXICO. Constitución Política de los Estados Unidos Mexicanos. Ciudad de México: FCE, 1994.

MÉXICO. Departamento de Salubridad Pública. Reglamento para la producción, introducción, transporte, depósito, y venta de leche y productos de la misma. Diario Oficial, p.837-838, 29 dic. 1925. 
MEXICO: Dairy Development Project, Reconnaissance Mission Report. PX01643: Dairy Development Project, L00200, R1990-110, 29006 B (World Bank Group Archive). 4 sep. 1984.

MÉXICO dejará de consumir leche fresca, tomaremos en polvo por la aftosa. Novedades, 23 abr. 1947.

MIEMBROS de la Junta Reguladora to gobernador del Distrito Federal, SP, SJ, c.4, exp.9. (Archivo Histórico de la Secretaría de Salud, Ciudad de México). 23 mar. 1926.

OCHOA, Enrique. Reappraising state intervention and social policy in Mexico: The case of milk in the Distrito Federal during the twentieth century. Mexican studies, v.15, n.1, p.73-99, 1999.

OFICIAL Mayor al gobernador del Distrito Federal, SP, SJ, c.4, exp.9 (Archivo Histórico de la Secretaría de Salud, Ciudad de México). 20 ago. 1925.

OTRO ESFUERZO por abaratar la leche. Excélsior, 27 ene. 1944.

OTRO MONOPOLIO en perspectiva. Excélsior, 4 nov. 1934.

PILCHER, Jeffrey. Que vivan los tamales!: Food and the making of Mexican identity. Albuquerque: University of New Mexico Press, 1998.

PRESCRIPCIONES generales para los expendios de leche. Ayuntamiento-Gobierno del Distrito Federal, Lecherías, v.1687 (Archivo Histórico del Distrito Federal, Ciudad de México). 30 ene. 1902.

PRODUCTORES de leche de Chalco to Miguel Alemán, MAV, exp.291, v.425.5/2-14 (Archivo General de la Nación, Ciudad de México). 17 ago. 1947.

QUIÉNES mangonean con la leche y cómo. $L a$ Prensa, 13 dic. 1943.

REGLAMENTO que daría margen a un monopolio. Excélsior, 15 jun. 1935.

REUNIÓN de los servicios de higiene para discutir las condiciones actuales del aprovisionamiento de leche en el DF, SP, HI, c.5, exp.1 (Archivo Histórico de la Secretaría de Salud, Ciudad de México). 8 oct. 1929.

RODRÍGUEZ KURI, Ariel. Desabasto, hambre y respuesta política, 1915. In: Illades, C. (ed.). Instituciones y ciudad: ocho estudios históricos sobre la ciudad de México. Ciudad de México: FP-SONES-Uníos, 2000. p.133-166.
ROMO, Luis Arturo; ROBLES, Gonzalo. Informe y recomendaciones para la reorganización del negocio de la leche, GR, v.77, exp.6 (Archivo General de la Nación, Ciudad de México). 17 mar. 1930.

ROSALES, Joaquín. Joaquín Rosales al jefe del Departamento de Salud Pública. SP, SJ caja 43 exp.14 (Archivo Histórico de la Secretaría de Salud, Ciudad de México). 28 ene. 1935.

SÁENZ, Áaron. Carta de Aarón Sáenz a Javier Gaxiola, ALR, v.524.2/33 (Archivo General de la Nación, Ciudad de México). 30 oct. 1934

SÁNCHEZ RÍOS, Feliciano. Resoluciones tomadas en la sesión, Estudio Sanitario de la Leche de Vaca, MAV, exp.1009, v.368/9868 (Archivo General de la Nación, Ciudad de México). oct. 1950.

SE PRETENDE acaparar toda la leche que se produzca en el D.F. La Prensa, 4 nov. 1934.

SECRETARÍA DE ECONOMÍA. Anuario Estadístico de la República Mexicana. Ciudad de México: 1952.

SECRETARIO General del Consejo Superior de Salubridad al Ayuntamiento. AyuntamientoGobierno del Distrito Federal, Lecherías, v.1687 (Archivo Histórico del Distrito Federal, Ciudad de México). 30 ene. 1902.

SIGUE faltando la leche en Veracruz. El Día, 25 feb. 1936.

SOLICITAN concesión. El Nacional, 7 sep. 1937.

SUBIRÁ el precio de la leche. Excélsior, 2 feb. 1949.

TALLER DE GRÁFICA POPULAR. El taller de gráfica popular: doce años de obra artística colectiva. Ciudad de México: La Estampa Mexicana, 1949.

TELEGRAMAS a Manuel Ávila Camacho, MAV, exp.523.1/24 [18, 28, 30, 31 nov. 1941] (Archivo General de la Nación, Ciudad de México). nov. 1941.

UNIÓN de Pequeños Productores de Leche Pro Granjas a Miguel Alemán, MAV, exp.290, v.425.5/28 (Archivo de General de la Nación). 8 ene. 1947.

UNIÓN Sindical de Vendedores y Repartidores de Leche del Distrito Federal a Manuel Ávila Camacho, MAC v.516, exp.523.1/24 (Archivo General de la Nación, Ciudad de México). 2 oct. 1943.

URGENCIA de que México consuma leche sana. El Nacional, 27 jul. 1947.

WEIS, Robert. Bakers and basques: a social history of bread in Mexico. Albuquerque: University of New Mexico Press, 2012. 